\title{
Study on Intelligent Terminal System Based on Andriod for Distance Learning
}

\author{
Jun-feng Zhang ${ }^{1}$, Ji-chun Zhao ${ }^{1, *}$, Guo-jie Wang ${ }^{2}$ \\ 1 Beijing Academy of Agriculture and Forestry Sciences, \\ The Research Center of Beijing Engineering technology for Rural Remote Information Services, \\ Beijing, China \\ 2 Handan Polytechnic College, Handan, Hebei, China \\ Zhaojc@agri.ac.cn
}

Keywords: Intelligent terminal; distance learning; Android system

\begin{abstract}
With the rapid development of network and information technology, intelligent terminal system is used in many fields. Intelligent terminal system based on Android operation system for distance learning is developed and introduced in the paper. The hardware and software design is given, and the effect is shown. The users can learn the video resources by the terminal system, and the terminal system can connect with TV or computer. The users reflect the system is easy to use, which can improve the learning efficiency.
\end{abstract}

\section{Introduction}

OTT is the abbreviation of The Top Over, which refers to the video service based on the open Internet and the service on the network, emphasizing the independence of the service and the physical network. Internationally, OTT set-top box refers to the integration of IP video and Internet applications through the public Internet TV transmission services. At present, the domestic OTT set-top boxes, mainly used to watch on-demand programs, enhance interaction and user experience. Through the wireless network connection, set-top box can also be achieved in the family of TV and smart phones, tablet computers and other interconnection. Smart set-top boxes are also considered as the first mature OTT application terminal. Radio and television operators, telecom operators, video network companies, etc. are also seen as the future development trend of OTT video services.

With the increasing market share of Android smart operating system, the current OTT set-top boxes are basically using Android system or its customized version, which has been recognized by the user in terms of presentation and application control. Apple Corp produced TV APPLE because of the closure of the operating license and the ecological system, has not been officially used in the country. At present, the mainstream Android set-top boxes main characteristic is:

- Video format is Compatible with MPEG-1/2/4 ASP, DivX 3/4/5, XviD, H.264(1920x1080p @ 30fps), SVC, MVC,VC-1, WMV, H.263, AVS, RMVB, RealVideo, and IPV6,

- Audio frequency format is Compatible with MPEG 1/2/2.5, Audio Layer 1/2/3, WMA Version 4, 4.1, 7, 8, 9, WMA Pro, PCM, Vorbis, Flac, ALAC, APE, AAC-LC, AAC-HE, AC-3, and DTS.

- Network stream supports HTML5, RTSP, and HLS.

- Software system upgrade is convenient.

- Wi-Fi and RJ45 network interface is supported.

OTT smart set-top boxes, IPTV set-top boxes and digital TV set-top boxes have their own characteristics, which are all competent from the point of video playback. OTT smart set-top boxes and IPTV set-top boxes have advantages in the QOS security. The contrast of OTT smart set-top boxes, IPTV set-top boxes and digital TV set-top boxes is shown in table 1. 
Table 1 the contrast of OTT smart set-top boxes, IPTV set-top boxes and digital TV set-top boxes

\begin{tabular}{|l|l|l|}
\hline & OTT smart set-top boxes & $\begin{array}{l}\text { IPTV set-top boxes and digital TV } \\
\text { set-top boxes }\end{array}$ \\
\hline Open system & $\begin{array}{l}\text { Based on the most popular open Android } \\
\text { system development, flexible } \\
\text { customization. }\end{array}$ & $\begin{array}{l}\text { Closed embedded systems, custom } \\
\text { development threshold higher. }\end{array}$ \\
\hline Wosted Network & $\begin{array}{l}\text { WIFI, 4G), nothing to do with the } \\
\text { operator, easy to deploy. }\end{array}$ & $\begin{array}{l}\text { Operator binding, need to be tied to } \\
\text { wiring port, mobility difference. }\end{array}$ \\
\hline Column information management & $\begin{array}{l}\text { According to need, support fast iterative } \\
\text { update. }\end{array}$ & $\begin{array}{l}\text { Operators closed and project } \\
\text { management. }\end{array}$ \\
\hline Construction and application costs & $\begin{array}{l}\text { Broadband access fee and one time set } \\
\text { top box fee. }\end{array}$ & $\begin{array}{l}\text { Broadband or cable access fee and } \\
\text { IPTV monthly rent. }\end{array}$ \\
\hline Service integration extension & $\begin{array}{l}\text { Open system, the third party service } \\
\text { access is convenient, and the application } \\
\text { for user friendly. }\end{array}$ & $\begin{array}{l}\text { Closed system, the integration of } \\
\text { third party applications, the user } \\
\text { experience is not friendly. }\end{array}$ \\
\hline
\end{tabular}

\section{Streaming media coding mode selection}

Streaming media refers to the form of media that transmits audio, video, and multimedia files in a network. Compared with download play form, the typical features of the streaming media is continuous audio and video information compressed into the network server, user can download and view the video without waiting for the entire file download complete. Because of the advantages of streaming media technology, the technology is widely used in video on demand, video conference, distance education, telemedicine and online live system.

H.264 is used as a video coding method in this paper. The H.264 is a video compression standard called MPEG-4 Part 10, or MPEG-4 AVC, which is senior encoding. It is set up by the ITU-T Video Coding Experts Group (VCEG) and the ISO/IEC Motion Picture Experts Group (MPEG) jointly promulgated standards. AAC is matched with H.264 audio formats, which is Advanced Audio Coding, based on the third part of the MPEG-4 standard formulation, H.264 and AAC in technology are MPEG-4 coding. The video encoding and decoding structure is shown in Figure 1.

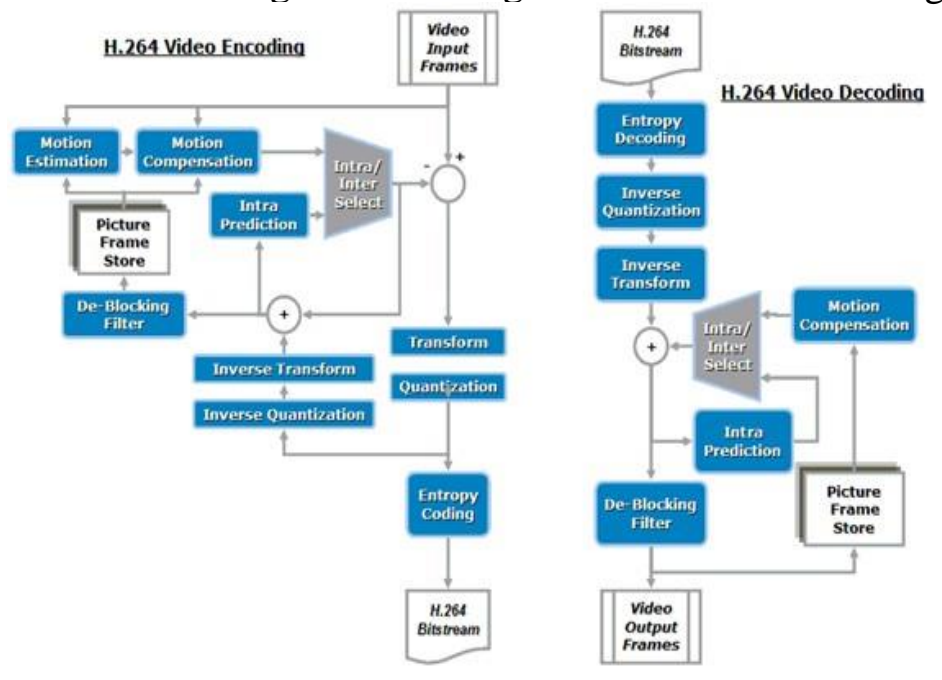

Figure 1 the video encoding and decoding structure is shown

\section{Hardware design}

The product uses quad core ARM Cortex-A7 architecture, clock frequency $1.3 \mathrm{GHz}$, eight nuclear GPU, and the Android operating system version is 4.4.2. The operation is simple, quick, practical. The biggest bright spot of is that it supports 1080p format in a variety of video decoding, especially 
1080p h.265 hardware decoding, and allow you to experience the most fluent, the HD family cinema. 4 The software design

4.1 System development process. The system is a B/S system, using MVC development model, JDK 1.5 version, and the mainstream development framework of SPRINGMVC and HIBERNATE. The database is Oracle, and web server is open source TOMCAT. The system development process is shown in Figure 2.

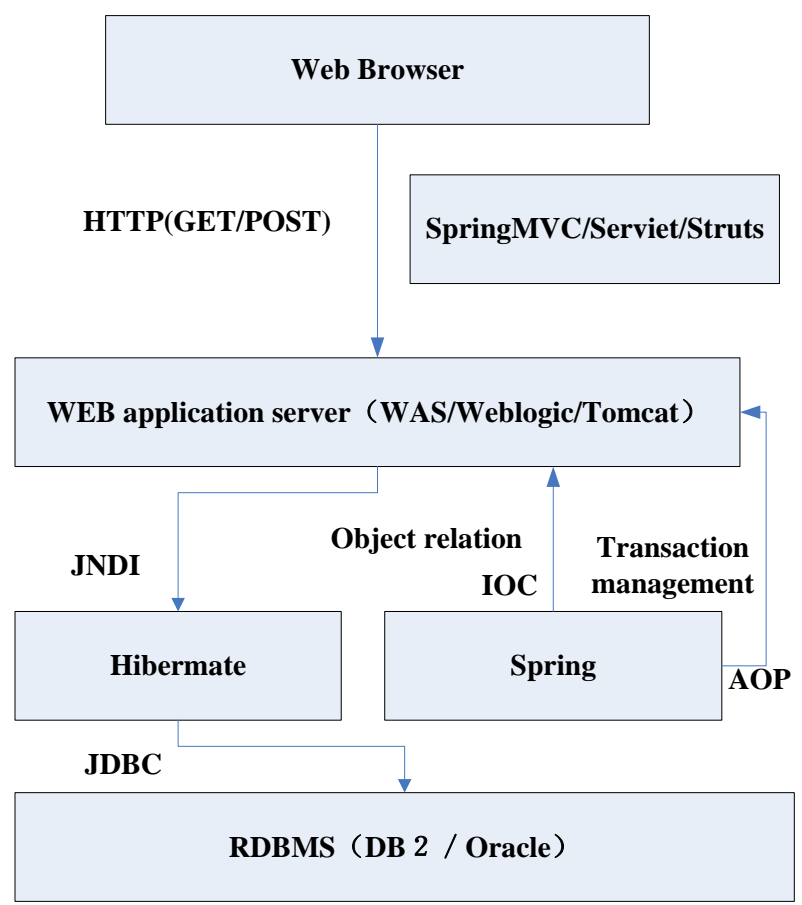

Figure 2 the system development process

4.2 System development structure. The system concludes five layers of access layer, application layer, business services and integration layer, infrastructure and services, and data layer. The access equipment can be TV, phone, pad or computer. The application concludes video management, video on demand, video live, information, learning feedback and application integration. The business services and integration concludes streaming media service, video editing service, full test search, web service, content publishing and management, report or data mining. The infrastructure and services concludes J2EE service and other service, and J2EE service contains AJAX, SPRING, HTML5, STRUCTS, XML/CSS and JQUARY, other service concludes file service and authorization service. The data layer main concludes database and file system. The System development structure is shown in Figure 3.

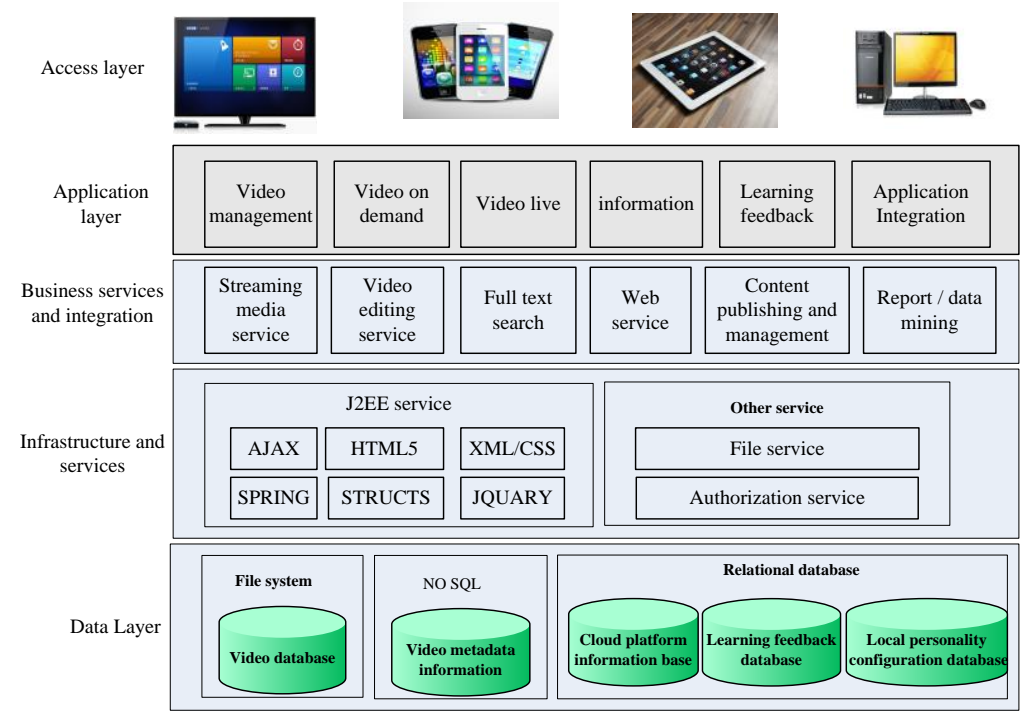

Figure 3 The System development structure 
4.3 The development of intelligent terminal client. In view of the current high-definition flat-panel TVs, the intelligent terminal client is developed based on the Android set-top box, and achieved a personalized information custom with a large screen display style. The intelligent terminal client system preliminary concludes six sections, which is live video, video on demand, information, service area, interactive area and personalized, specific content can be flexibly customized according to the actual demand. At the same time, the system supports the download of learning courseware and the local play function, and can solve the bottleneck problem of network transmission bandwidth.

4.4 Video live function designs. The video live function interface is shown as follows:

SECRECY = "d69b468014d37a9d7d";

Sign $=($ deviceId + SECRECY $)$ md5

URL: http://134.212.18/tvserver/api/v1/getLiveList.action

Support mode: JSON

HTTP request mode: POST

\section{5 test results and conclusion}

When the Intelligent terminal system based on Android operation system for distance learning is finished, we start to test the system. The result show that the video playing smoothly, and the system works stable. The users for distance learning reflect that the system is easy to use and can improve their learning efficiency. In the test, intelligent terminal system based on Android operation system for distance learning is developed and introduced. The hardware and software design is given, and the effect is shown. The users can learn the video resources by the terminal system, and the terminal system can connect with TV or computer. The users reflect the system is easy to use, which can improve the learning efficiency. It makes users study convenient, and has broad application prospects.

\section{Acknowledgment}

This work was sponsored by Beijing Science and Technology Program Support (Project No. Z151100002115029), which is development of intelligent multi terminal system for modern distance learning in rural areas, and supported by Distance Learning Innovation Team Project of Beijing Academy of Agriculture and Forestry Sciences (Project No. JNICST201612 ).

\section{References}

[1] N Hood, A Littlejohn, C Milligan. Context counts: How learners' contexts influence learning in a MOOC [J]. Computers \& Education, 2015, 91: 83-91.

[2] Yongsheng Wang, Máire O'Neill, Fatih Kurugollu, Elizabeth O'Sullivan, Privacy region protection for H.264/AVC with enhanced scrambling effect and a low bitrate overhead[J].Signal Processing: Image Communication, Volume 35, July 2015, Pages 71-84.

[3] Ibrahim Almarashdeh, Sharing instructors experience of learning management system: A technology perspective of user satisfaction in distance learning course [J].Computers in Human Behavior, Volume 63, October 2016, Pages 249-255.

[4] T. Messaoudi, F. Bodin, J.J. Hidalgo Diaz, S. Ichihara, T. Fikry, I. Lacreuse, P. Liverneaux, S. Facca, Evaluation of a new eLearning platform for distance teaching of microsurgery[J]. Chirurgie de la Main, Volume 34, Issue 3, June 2015, Pages 109-112.

[5] MOONEY R J, ROY L. Content-based book recommending using learning for text categorization [C], Proceedings of the SIGIR-99 Workshop on Recommender Systems: Algorithms and Evaluation. Berkeley, A CM, 1999. 